\title{
OPEN Effects of nitrogen application rate on the photosynthetic pigment, leaf fluorescence characteristics, and yield of indica hybrid rice and their interrelations
}

Jinfeng Peng ${ }^{1}$, Yuehua Feng ${ }^{1,2 \bowtie}$, Xiaoke Wang ${ }^{1}$, Jie $\mathrm{Li}^{1}$, Guiling Xu ${ }^{1 凶}$, Somsana Phonenasay ${ }^{1}$, Qiangxin Luo ${ }^{1}$, Zhili Han ${ }^{1} \&$ Wei Lu

A field experiment employing the rice cultivars Qyou6 and Yixiangyou2115 as materials and different nitrogen application rates was conducted in Huangping County, Guizhou Province in 2019 to determine the effects of nitrogen application rate on photosynthetic pigments, leaf fluorescence characteristics, yield, and their interrelations in indica hybrid rice. The results showed that photosynthetic pigment contents generally increased with increasing nitrogen application rate. As the nitrogen rate increased, the maximal quantum yield of $\mathrm{PSII}\left(\mathrm{F}_{\mathrm{v}} / \mathrm{F}_{\mathrm{m}}\right)$, actual quantum yield of PSII $\left(\Phi_{\text {PSIII }}\right)$, and relative electron transfer rate at PSII (ETR) first decreased and then increased at the booting stage; $F_{\mathrm{v}} / F_{\mathrm{m}}$ and $\Phi_{\text {PSII }}$ decreased while ETR first increased and then decreased at the heading stage; nevertheless, $F_{\mathrm{v}} / F_{\mathrm{m}}$ and $\Phi_{\mathrm{PSSI}}$ first decreased and then increased but ETR was just the opposite at the maturity stage. Non-photochemical quenching coefficient (qN) and quantum yield of regulatory energy dissipation at PSII (Y(NPQ)) first increased and then decreased whereas quantum yield of non-regulatory energy dissipation at PSII ( $Y(N O)$ ) first decreased and then increased at the booting, heading, and maturity stages with increasing nitrogen application rate. Photochemical quenching coefficient (qP) showed an increasing trend as the nitrogen rate increased in the range of 150-300 kg/ha at the heading and maturity stages. Photosynthetic pigments, leaf fluorescence characteristics, and yield and its components were significantly correlated. First, chlorophylls a and b were significantly negatively correlated with $F_{v} / F_{m}$ while significantly positively correlated with $\mathrm{qP}$ at the heading stage. Secondly, Carotenoids were significantly positively correlated with the effective panicle number (EPN) at the booting stage while significantly negatively correlated with the spikelets per panicle (SPP) at the heading stage. Chlorophyll a and carotenoids were significantly positively correlated with EPN but significantly negatively correlated with spikelet filling (SF) at the maturity stage. In addition, $\mathrm{QP}$ was significantly negatively correlated with EPN at the booting stage. At the heading stage, $F_{v} / F_{m}$ and $Y(N O)$ were significantly negatively correlated with EPN and $S P P$, respectively, and $F_{v} / F_{m}$ and $\Phi_{\text {PSII }}$ were significantly positively related to $S F$. Moreover, $q P$ was extremely significantly positively related to $E P N$ whereas $F_{v} / F_{m}$ was extremely significantly negatively correlated with grain yield at the maturity stage. Appropriate nitrogen application rates can enhance photosynthetic pigment contents, improve the photochemical efficiency and proportion of the open part of the reaction center of PSII, and promote the quantum efficiency and self-protection ability of PSII, thereby increasing photosynthetic efficiency and yield. Under the conditions adopted in this experiment, a parabolic relationship was observed between the nitrogen application rate and grain yield. The regression analysis results showed that the best nitrogen application rate of indica hybrid rice is $168.16 \mathrm{~kg} \mathrm{ha}^{-1}$ and the highest yield is $11,804.87 \mathrm{~kg} \mathrm{ha}^{-1}$.

${ }^{1}$ College of Agronomy, Guizhou University, Guiyang 550025, China. ${ }^{2}$ Key Laboratory of Plant Resource Conservation and Germplasm Innovation in Mountainous Region (Ministry of Education), Guizhou University, Guiyang 550025, China. ${ }^{\bowtie}$ email: fengyuehua2006@126.com; xuguiling2007@126.com 
Nitrogen is an important factor for increasing rice yield. Among the many factors that could promote rice yield, the contribution of nitrogen fertilizer exceeds $40 \%{ }^{1}$. Nitrogen supply during rice growth and development not only exerts evident regulatory effects on leaf photosynthetic characteristics, stalk and sheath storage output and transport, grain carbohydrate accumulation, and sinks source balance, but also has a close relationship with grain filling and yield ${ }^{2,3}$. Lin et al. ${ }^{4}$ found that long-term non-application of nitrogen causes soil nitrogen and fertility to decrease, which reduces crop yields, whereas application of nitrogen fertilizer increases the total nitrogen content of the soil; this study further found that the proper application of nitrogen has a significant effect on crop yield.

The supply of nutrients in the cultivation environment is directly related to the photosynthetic function of crop leaves ${ }^{5}$. The photosynthetic pigments of higher plants include chlorophyll and carotenoids ${ }^{6}$. Chlorophyll is an important pigment involved in the absorption, transmission, and transformation of light energy in photosynthesis ${ }^{7}$. Several studies have indicated that nitrogen nutrition plays an important role in the regulation of photosynthetic pigment synthesis in crop leaves, and that the level of nitrogen supply has a significant positive correlation with the chlorophyll content of $\mathrm{crops}^{8,9}$. Therefore, when the crop lacks nitrogen, its chlorophyll content decreases, its photosynthetic efficiency weakens, carbohydrate synthesis is blocked, and crop yield declines ${ }^{10}$.

Chlorophyll fluorescence emitted by plants is also closely related to various reaction processes in photosynthesis and may contain rich information about photosynthetic changes. Scholars at home and abroad have carried out considerable research on the effect of nitrogen application on the fluorescence characteristics and yield properties of crop leaves ${ }^{11-15}$. Nevertheless, different research conclusions on the relationship between nitrogen application and fluorescence characteristics of rice leaves have been reported. Xu et al. ${ }^{13}$, for example, demonstrated that, under the same irrigation mode, proper nitrogen treatment could increase $\mathrm{F}_{\mathrm{v}} / \mathrm{F}_{\mathrm{m}}$ in rice leaves. However, Ma et al. ${ }^{16}$ showed that $\mathrm{F}_{\mathrm{v}} / \mathrm{F}_{\mathrm{m}}$ in rice leaves increases with increasing nitrogen application under three nitrogen supply levels in field experiments.

Research on the relationships among rice leaf photosynthetic pigments, fluorescence characteristics, and yield properties is limited. For instance, Liu et al. ${ }^{17}$ only used an indica japonica hybrid as an experimental material to study the relationship between chlorophyll content and rice yield components. Yan et al. ${ }^{18}$ only studied the relationship between chlorophyll content and several fluorescence parameters $\left(\mathrm{F}_{\mathrm{v}} / \mathrm{F}_{\mathrm{m}}, \mathrm{F}_{\mathrm{v}} / \mathrm{F}_{\mathrm{o}}, \mathrm{ETR}\right)$ after the full spreading of rice flag leaves. Xu et al. ${ }^{13}$ studied the relationship between $\mathrm{F}_{\mathrm{v}} / \mathrm{F}_{\mathrm{o}}, \mathrm{F}_{\mathrm{v}} / \mathrm{F}_{\mathrm{m}}$, and rice yield at the middle tillering and heading stages under the condition of pool planting only. Guo et al. ${ }^{19}$ explored the relationships among a limited number of fluorescence parameters, including $\mathrm{F}_{\mathrm{v}} / \mathrm{F}_{\mathrm{m}}, \Phi_{\mathrm{PSII}}, \mathrm{qP}$, and $\mathrm{qN}$, and yield traits after rice heading.

In the present study, photosynthetic pigments, leaf fluorescence characteristics, yield and its components were determined in two indica hybrid rice cultivars under five nitrogen application rates in 2019. The purpose of this study is to explore the effects of nitrogen application rate on photosynthetic pigments, leaf fluorescence characteristics, yield, and their interrelations in indica hybrid rice.

\section{Results}

Photosynthetic pigments in rice leaf blades. The contents of chlorophylls $\mathrm{a}$, and $\mathrm{b}$ and carotenoids showed an upward trend with increasing nitrogen application rate. Pigments in the N4 treatment were significantly higher than those in the N1 treatment at the heading and maturity stages (Fig. 1).

Photochemical efficiency of rice leaf blades. Photochemical efficiency is calculated from to the number of photons of the product obtained by the effective photochemical reaction divided by the total quantum number of light absorbed. $\mathrm{F}_{\mathrm{v}} / \mathrm{F}_{\mathrm{m}}$ represents the maximum photosynthetic quantum yield of the reaction center of PSII and reflects the internal light energy conversion efficiency or maximum light energy conversion efficiency of PSII; this characteristic may indicate the photosynthetic potential of crops ${ }^{20}$. $\Phi_{\text {PSII }}$ represents the actual photosynthetic quantum yield of PSII and reflects the actual primary light energy capture efficiency of the reaction center of PSII when it is partially closed ${ }^{21}$. ETR reflects the actual electron transfer rate of PSII ${ }^{21}$.

As the nitrogen application rate increased, $\mathrm{F}_{\mathrm{v}} / \mathrm{F}_{\mathrm{m}}$ first decreased and then increased at the booting and maturity stages but decreased at the heading stage. $\mathrm{F}_{\mathrm{v}} / \mathrm{F}_{\mathrm{m}}$ in the $\mathrm{N} 3$ treatment was the highest and significantly higher than that in the $\mathrm{N} 2$ treatment at the booting stage. Moreover, $\mathrm{F}_{\mathrm{v}} / \mathrm{F}_{\mathrm{m}}$ in the N0 treatment was the highest and significantly higher than those in the N2, N3, and N4 treatments at the heading and maturity stages (Fig. 2).

As the nitrogen application rate increased, $\Phi_{\mathrm{PSII}}$ first decreased and then increased at the booting stage, decreased at the heading stage, and then increased at the maturity stage. Compared with those of other treatments, $\Phi_{\mathrm{PSII}}$ in the N0 treatment was significantly higher than those in the N1, N2, and N4 treatments at the booting stage. Among the treatments studied, the N0 treatment showed the highest $\Phi_{\text {PSII }}$ at the heading stage, but no significant difference was observed among the five nitrogen application treatments. $\Phi_{\mathrm{PSII}}$ in the N4 treatment was the highest and significantly higher than that in the N0 and N2 treatments at the maturity stage (Fig. 2).

ETR showed a downward trend followed by an upward trend at the booting stage. However, at the heading and maturity stages, ETR first increased and then decreased. The highest ETR were observed in the N3 treatment at the heading stage and in the N1 treatment at the maturity stage, although differences between the treatments were not significant. ETR in the N0 treatment was highest and significantly higher than that in the N2 treatment at the booting stage (Fig. 2).

Fluorescence quenching coefficient of rice leaf blades. Fluorescence quenching may be categorized as photochemical quenching and non-photochemical quenching. Photochemical quenching is represented by $\mathrm{qP}$, which reflects the degree of reaction center opening in the redox state of the original electron acceptor QA of PSII $^{21}$, while non-photochemical quenching is represented by $\mathrm{qN}$, which reflects the part of light energy absorbed by pigments of the PSII antenna and dissipated in the form of heat instead of being used for photosynthetic electron transfer ${ }^{22}$. 

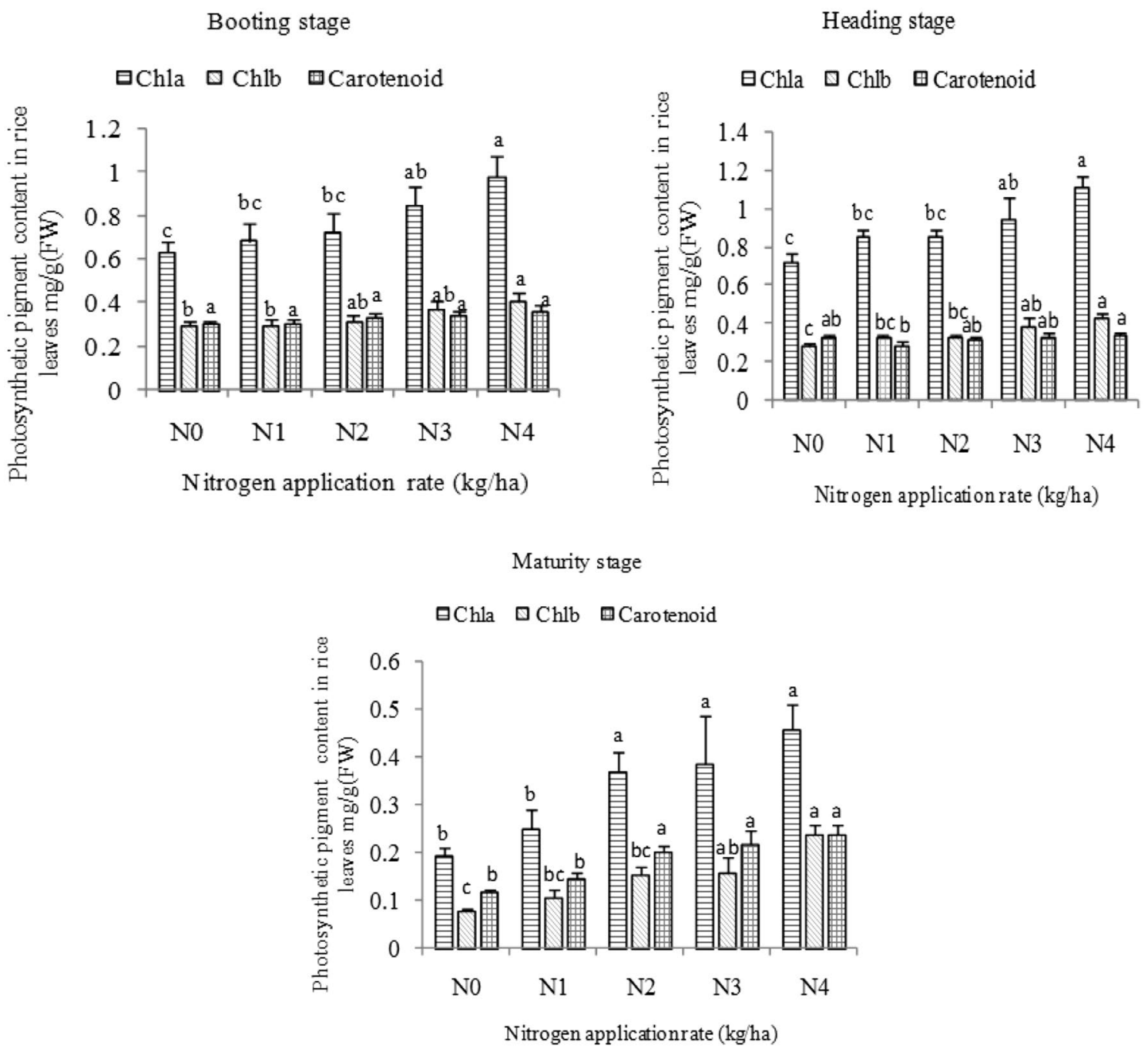

Figure 1. Effects of different nitrogen application rates on photosynthetic pigments in rice leaves. Note N0:0 kg ha ${ }^{-1}$; N1:75 kg ha ${ }^{-1}$; N2:150 kg ha-1; N3: $225 \mathrm{~kg} \mathrm{ha}^{-1}$; N4:300 kg ha' ${ }^{-1}$; Chla, chlorophyll (a); Chlb, chlorophyll (b); significant differences between rice varieties and nitrogen treatments $(P<0.05)$ are indicated by lowercase letters; vertical bars represent SE $(n=3)$. The data in the figure is the average value of the two cultivars.

Figure 3 demonstrates that the effect of nitrogen application rate on $\mathrm{qP}$ is not evident at the booting stage. However, qP increased at the heading stage, and first decreased and then increased at the maturity stage with increasing nitrogen application rate. Among the qPs obtained, that inthe qPs obtained, that in the N4 treatment was the highest. The qP in N4 was also significantly higher than that inin N1 and N2 at the heading stage. Similarly, the qP in the N4 treatment was the highest at the maturity stage, but no significant difference was found among treatments. qN first increased and then decreased at the booting, heading, and maturity stages with increasing nitrogen rate. Among the qNs obtained, that in the $\mathrm{N} 2$ treatment was the highest and significantly higher than that in N3 at the booting and maturity stages. Moreover, among the qNs obtained, the qN in the N3 treatment was the highest and significantly higher than that in the N1 treatment in the heading stage.

Non-photochemical quenching quantum yield of rice leaf blades. Y(NPQ) refers to the quantum yield of regulatory energy dissipation at PSII, which is an important index of light protection ${ }^{20}$, while $\mathrm{Y}(\mathrm{NO})$ refers to the quantum yield of non-regulatory energy dissipation at PSII, which is an important index of light damage ${ }^{20}$.

$\mathrm{Y}(\mathrm{NPQ})$ first increased and then decreased at the booting, heading, and maturity stages with increasing nitrogen application rate. The Y(NPQ) in the N2 treatment was the highest among the results obtained and significantly higher than that in the N3 treatment at the booting and maturity stages. However, at the heading stage, the highest $\mathrm{Y}(\mathrm{NPQ})$ was observed in the N1 treatment, although no significant difference occurred between the five nitrogen application rates. $\mathrm{Y}(\mathrm{NO})$ first decreased and then increased at the booting, heading, and maturity stages as the nitrogen rate increased (Fig. 4). The $\mathrm{Y}(\mathrm{NO})$ values in the $\mathrm{N} 2$ and N3 treatments were highest at the booting and heading stages, respectively, and no significant difference was observed among all $\mathrm{N}$ 

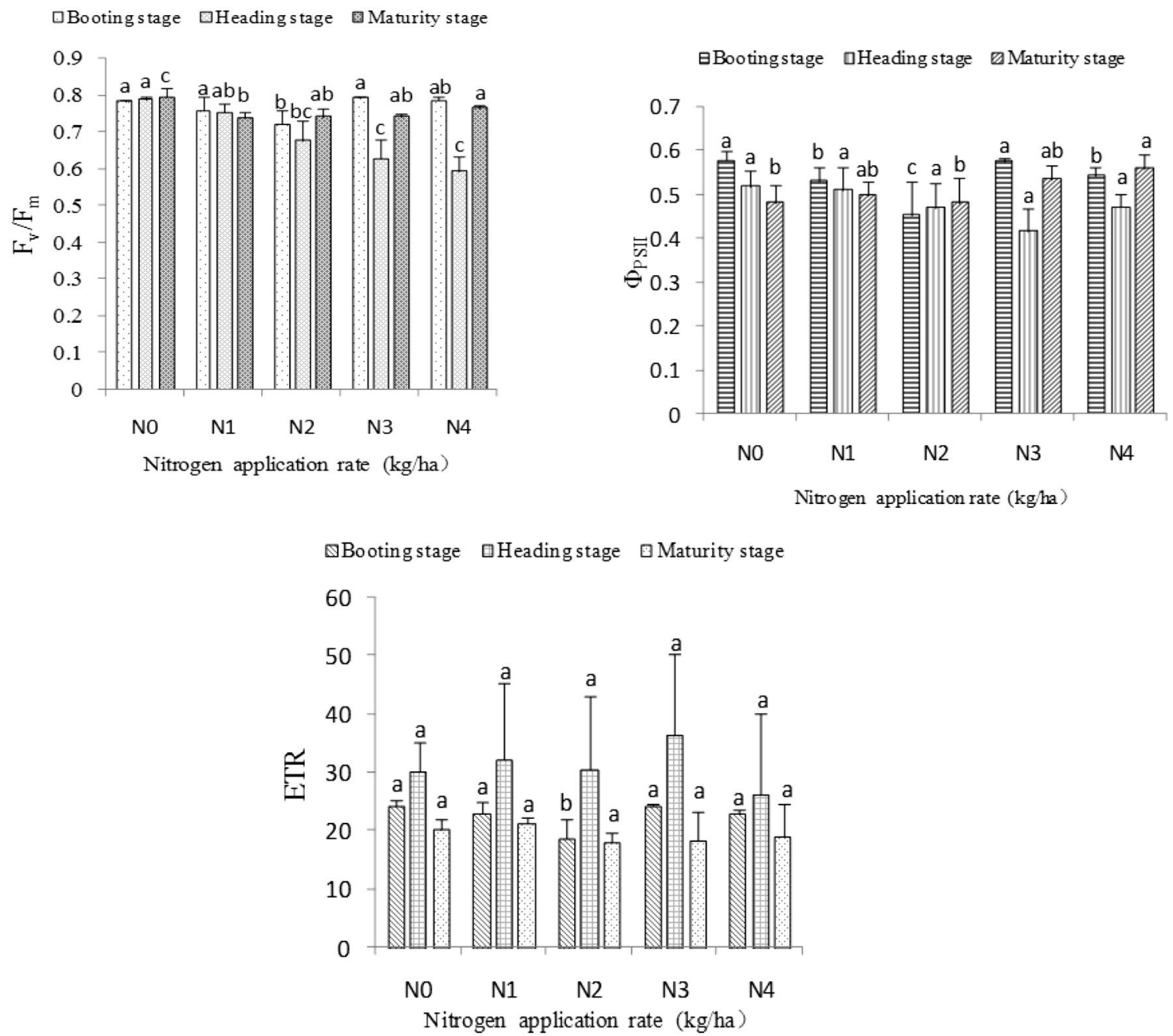

Figure 2. Effects of different nitrogen application rates on the photochemical efficiency of rice leaves.

$\square$ Booting stage $\square$ Heading stage $\square$ Maturity stage

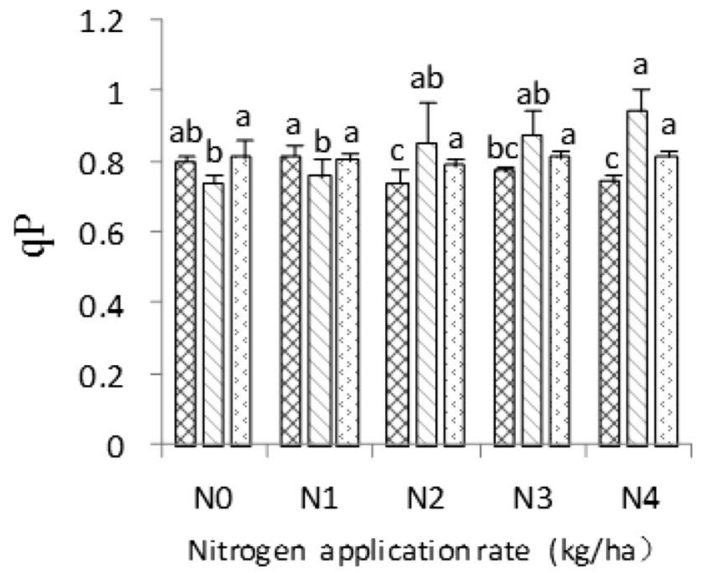

Booting stage $\boxminus$ Heading stage $\square$ Maturity stage

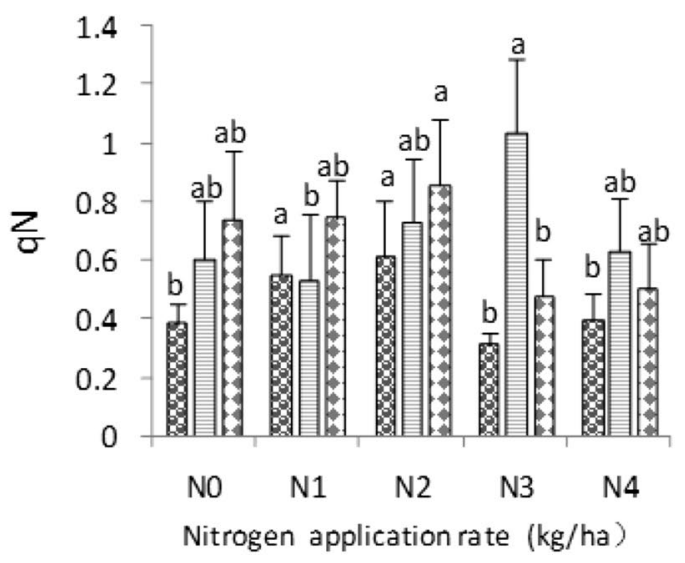

Figure 3. Effects of different nitrogen application rates on the fluorescence quenching coefficients of rice leaves.

treatments. The $\mathrm{Y}(\mathrm{NO})$ in the $\mathrm{N} 3$ treatment was significantly higher than those in the $\mathrm{N} 1, \mathrm{~N} 2$, and $\mathrm{N} 4$ treatments at the maturity stage (Fig. 4).

Yield and its components. The grain yield first increased and then decreased with increasing nitrogen application rate (Table 1), and the grain yield of the $\mathrm{N} 2$ treatment was the highest and significantly higher than 
$\boxplus$ Booting stage $\square$ Heading stage $\boxplus$ Maturity stage

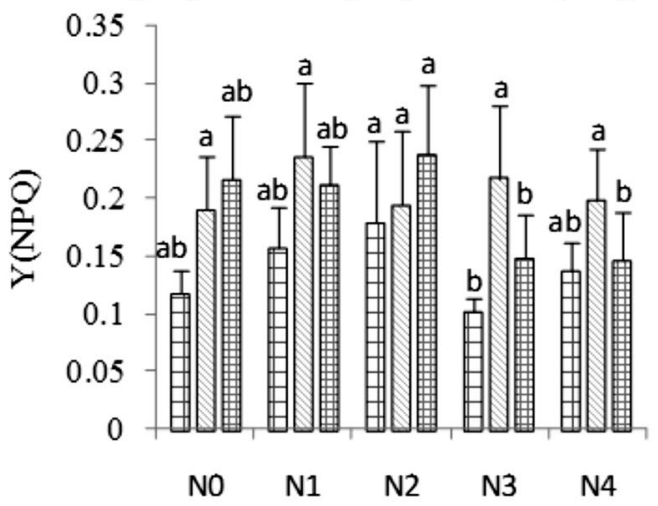

Nitrogen application rate $(\mathrm{kg} / \mathrm{ha})$

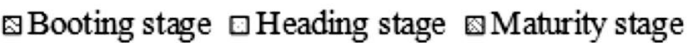

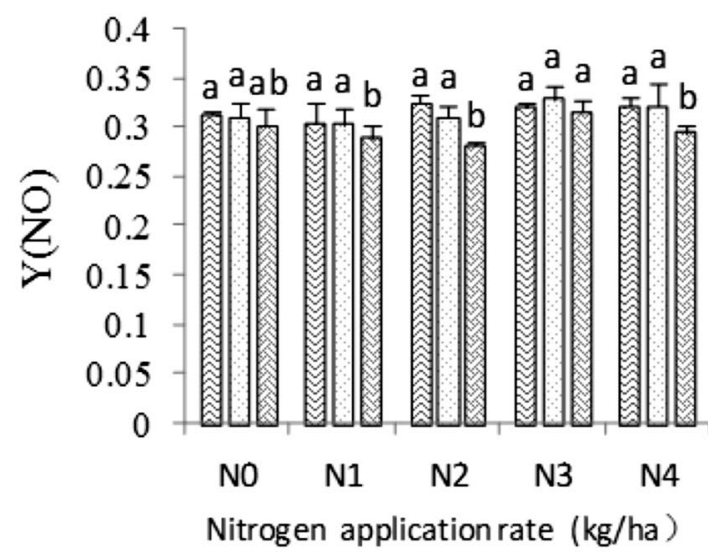

Figure 4. Effects of different nitrogen application rates on the quantum yield of non-photochemical quenching.

\begin{tabular}{|c|c|c|c|c|c|}
\hline Treatment & $\begin{array}{l}\text { Effective panicle } \\
\text { number }\left(\mathbf{m}^{-2}\right)\end{array}$ & Spikelets per panicle & $\begin{array}{l}\text { Thousand-grain weight } \\
\text { (g) }\end{array}$ & Spikelet filling (\%) & Grain yield $\left(\mathrm{kg} \mathrm{ha}^{-1}\right)$ \\
\hline No & $194.91 \mathrm{ab}$ & $208.20 \mathrm{a}$ & $34.50 \mathrm{a}$ & $86.14 \mathrm{a}$ & $10,569 \mathrm{c}$ \\
\hline N1 & $188.43 \mathrm{~b}$ & $215.55 \mathrm{a}$ & $33.98 \mathrm{~b}$ & $83.81 \mathrm{ab}$ & $11,553 \mathrm{ab}$ \\
\hline N2 & $205.56 \mathrm{ab}$ & $211.39 \mathrm{a}$ & $33.82 \mathrm{bc}$ & $82.32 \mathrm{~b}$ & $11,882 \mathrm{a}$ \\
\hline N3 & $206.48 \mathrm{ab}$ & $205.10 \mathrm{a}$ & $33.56 \mathrm{c}$ & $80.88 \mathrm{~b}$ & $11,446 \mathrm{ab}$ \\
\hline N4 & $215.28 \mathrm{a}$ & $204.42 \mathrm{a}$ & $33.79 \mathrm{bc}$ & $82.01 \mathrm{~b}$ & $11,187 \mathrm{~b}$ \\
\hline $\mathrm{V} 1$ & $205.37 \mathrm{a}$ & $237.79 \mathrm{a}$ & $31.31 \mathrm{~b}$ & $79.73 \mathrm{~b}$ & $12,445 \mathrm{a}$ \\
\hline V2 & $198.89 \mathrm{a}$ & $180.08 \mathrm{~b}$ & $36.55 \mathrm{a}$ & $86.33 \mathrm{a}$ & $10,210 \mathrm{~b}$ \\
\hline $\mathrm{V}$ & 0.68 & $136.35^{\star *}$ & $1836.91^{* *}$ & $22.80^{*}$ & $99.94^{* *}$ \\
\hline $\mathrm{N}$ & 1.43 & 0.70 & $11.98^{* *}$ & $3.22^{*}$ & $6.64^{\star *}$ \\
\hline $\mathrm{V}^{\star} \mathrm{N}$ & 0.12 & 0.63 & $3.76^{*}$ & 1.59 & $5.62^{\star *}$ \\
\hline
\end{tabular}

Table 1. Yield and its component under different treatments in rice. Note Significant differences between rice varieties and nitrogen treatments $(P<0.05)$ are indicated by lowercase letters, and ${ }^{*}$ and ${ }^{* *}$ indicate significant effects $(P<0.05)$ and extremely significant effects $(P<0.01)$, respectively. The data in the table is the average value of the two cultivars. The same as below.

those of the N0 and N4 treatments. The regression equation between grain yield $(y)$ and nitrogen application rate $(x)$ was $y=-0.0413 x^{2}+13.89 x+10,637\left(R^{2}=0.9121, P<0.01\right)$. The best nitrogen application rate of rice was $168.16 \mathrm{~kg} \mathrm{ha}^{-1}$, and the highest yield was $11,804.87 \mathrm{~kg} \mathrm{ha}^{-1}$. The effective panicle number (EPN), thousand-grain weight (TGW), and spikelet filling (SF) first decreased and then increased with increasing nitrogen application rate. In particular, the EPN of the N4 treatment was the highest and significantly higher than that of the N1 treatment. The TGW and SF of the N0 treatment were the highest and significantly higher than those of the N2, N3, and N4 treatments. The spikelets per panicle (SPP) first increased and then decreased with increasing nitrogen application rate. Here, the SPP of the N2 treatment was the highest, although no significant difference was observed among all treatments (Table 1).

Between the two rice cultivars studied, the EPN, SPP, and grain yield of V1 were higher than those of V2. However, the TGW and SF of the former cultivar were lower than those of the latter. In particular, the SPP and grain yield of V1 were significantly higher than those of V2 (Table 1).

The results of variance analysis showed that differences in the SPP, TGW, and grain yield between rice varieties were extremely significant, and SF displayed significantly different. Significant differences in TGW, SF, and grain yield were observed among the nitrogen application rates. The interactions of these characteristics between varieties and nitrogen application rates were not significant except for TGW and grain yield (Table 1).

Relationship between photosynthetic pigments and fluorescence parameters in rice leaf blades. At the booting stage, photosynthetic pigments in leaf blades were negatively correlated with Y(NPQ), $\mathrm{qP}$, and qN but positively correlated with Fv/Fm and $\mathrm{Y}(\mathrm{NO})$; however, the correlations observed did not reach significant levels $(P>0.05)$. At the heading stage, photosynthetic pigments in leaf blades were negatively correlated with $\mathrm{F}_{\mathrm{v}} / \mathrm{F}_{\mathrm{m}}, \Phi_{\mathrm{PSII}}$, and ETR but positively correlated with $\mathrm{Y}(\mathrm{NO}), \mathrm{qP}$, and $\mathrm{qN}$. Chlorophylls a and b were significantly correlated with $\mathrm{F}_{\mathrm{v}} / \mathrm{F}_{\mathrm{m}}, \mathrm{qP}$. At the maturity stage, leaf photosynthetic pigments were negatively correlated with $\mathrm{F}_{\mathrm{v}} / \mathrm{F}_{\mathrm{m}}, \mathrm{ETR}, \mathrm{Y}(\mathrm{NPQ})$, $\mathrm{qP}$, and $\mathrm{qN}$ but positively correlated with $\Phi_{\mathrm{PSI}}$, however, the correlations found did not reach significant levels $(P>0.05)$ (Table 2). 


\begin{tabular}{|c|c|c|c|c|c|c|c|c|}
\hline Growth period & Item & $\mathrm{F}_{\mathrm{v}} / \mathrm{F}_{\mathrm{m}}$ & $\Phi_{\text {PSII }}$ & qP & qN & $\mathrm{Y}(\mathrm{NPQ})$ & $\mathrm{Y}(\mathrm{NO})$ & ETR \\
\hline \multirow{3}{*}{ Booting stage } & Chla & 0.391 & 0.089 & -0.623 & -0.398 & -0.205 & 0.541 & 0.044 \\
\hline & Chlb & 0.519 & 0.231 & -0.579 & -0.547 & -0.364 & 0.547 & 0.171 \\
\hline & Carotenoid content & 0.252 & -0.049 & -0.795 & -0.344 & -0.145 & 0.749 & -0.126 \\
\hline \multirow{3}{*}{ Heading stage } & Chla & $-0.912^{*}$ & -0.533 & $0.914^{*}$ & 0.227 & 0.073 & 0.648 & -0.307 \\
\hline & Chlb & $-0.928^{*}$ & -0.621 & $0.907^{*}$ & 0.342 & 0.126 & 0.732 & -0.181 \\
\hline & Carotenoid content & -0.509 & -0.347 & 0.566 & 0.340 & -0.741 & 0.693 & -0.344 \\
\hline \multirow{3}{*}{ Maturity stage } & Chla & -0.405 & 0.763 & -0.014 & -0.558 & -0.632 & -0.010 & -0.720 \\
\hline & Chlb & -0.241 & 0.821 & -0.152 & -0.581 & -0.662 & -0.055 & -0.567 \\
\hline & Carotenoid content & -0.450 & 0.768 & -0.014 & -0.587 & -0.655 & 0.060 & -0.735 \\
\hline
\end{tabular}

Table 2. Relationship between photosynthetic pigments and fluorescence parameters in rice leaves. Note Chla, chlorophyll a; Chlb, chlorophyll b.

\begin{tabular}{|c|c|c|c|c|c|c|c|c|c|c|c|}
\hline \multirow[b]{2}{*}{ Growth period } & \multirow[b]{2}{*}{ Item } & \multicolumn{3}{|c|}{ Photosynthetic pigment } & \multicolumn{7}{|c|}{ Fluorescence parameter } \\
\hline & & chla & chlb & Carotenoid content & $\mathrm{F}_{\mathrm{v}} / \mathrm{F}_{\mathrm{m}}$ & $\Phi_{\text {PSII }}$ & qP & qN & $\mathrm{Y}(\mathrm{NPQ})$ & $\mathrm{Y}(\mathrm{NO})$ & ETR \\
\hline \multirow{5}{*}{ Jointing stage } & GY & 0.163 & 0.01 & 0.232 & -0.696 & -0.761 & -0.389 & 0.626 & 0.667 & 0.297 & -0.72 \\
\hline & EPN & 0.871 & 0.871 & $0.964^{* *}$ & 0.177 & -0.12 & $-0.892^{\star}$ & -0.31 & -0.102 & 0.863 & -0.223 \\
\hline & SPP & -0.702 & -0.807 & -0.746 & -0.683 & -0.481 & 0.491 & 0.813 & 0.674 & -0.61 & -0.363 \\
\hline & SF & -0.759 & -0.714 & -0.803 & 0.014 & 0.231 & 0.105 & 0.618 & -0.008 & -0.619 & 0.263 \\
\hline & TGW & -0.705 & -0.649 & -0.728 & 0.052 & 0.245 & 0.525 & 0.042 & -0.05 & -0.515 & 0.257 \\
\hline \multirow{5}{*}{ Heading stage } & GY & 0.249 & 0.24 & -0.493 & -0.378 & -0.441 & 0.332 & 0.259 & 0.389 & -0.039 & 0.271 \\
\hline & EPN & 0.787 & 0.778 & 0.764 & $-0.913^{*}$ & -0.648 & $0.953^{* *}$ & 0.444 & -0.479 & 0.751 & -0.331 \\
\hline & SPP & -0.479 & -0.594 & $-0.942^{\star *}$ & 0.652 & 0.56 & -0.657 & -0.538 & 0.482 & $-0.884^{*}$ & 0.122 \\
\hline & SF & -0.742 & -0.787 & -0.161 & $0.895^{*}$ & $0.901^{\star}$ & -0.825 & -0.693 & -0.223 & -0.699 & -0.27 \\
\hline & TGW & -0.711 & -0.757 & -0.028 & 0.84 & 0.865 & -0.757 & -0.655 & -0.35 & -0.627 & -0.327 \\
\hline \multirow{5}{*}{ Maturity stage } & GY & 0.459 & 0.301 & 0.483 & $-0.935^{* *}$ & -0.008 & 0.771 & 0.207 & 0.149 & -0.449 & -0.436 \\
\hline & EPN & $0.915^{*}$ & $0.911^{*}$ & $0.899^{*}$ & -0.036 & 0.7 & 0.176 & -0.557 & -0.615 & 0.11 & -0.779 \\
\hline & SPP & -0.564 & -0.586 & -0.567 & -0.361 & -0.696 & -0.66 & 0.78 & 0.775 & -0.629 & 0.518 \\
\hline & SF & $-0.881^{\star}$ & -0.75 & $-0.917^{\star}$ & 0.719 & -0.651 & 0.404 & 0.542 & 0.589 & -0.158 & 0.704 \\
\hline & TGW & -0.827 & -0.692 & -0.867 & 0.8 & -0.617 & 0.17 & 0.506 & 0.551 & 0.128 & 0.62 \\
\hline
\end{tabular}

Table 3. Relationship between rice yield and its components, photosynthetic pigments, and fluorescence parameters. Note GY, grain yield; EPN, effective panicle number; SPP, spikelets per panicle; SF, seed setting rate; TGW, thousand-grain weight.

Relationships among rice yield and its components, photosynthetic pigments, and fluorescence parameters. At the booting stage, carotenoids had a significant positive correlation with EPN. At the heading stage, carotenoids had a significant negative correlation with SPP. At the maturity stage, chlorophylls a and $\mathrm{b}$ and carotenoids had significant positive correlations with EPN. However, chlorophyll a and carotenoids had a significant negative correlation with SF (Table 3).

At the booting stage, $\mathrm{qP}$ was negatively correlated with EPN at the 5\% significance level, and the correlation coefficient was -0.892 . At the heading stage, $\mathrm{F}_{\mathrm{v}} / \mathrm{F}_{\mathrm{m}}$ and $\mathrm{Y}(\mathrm{NO})$ were negatively correlated with EPN and SPP $(P<0.05)$ with correlation coefficients of -0.913 and -0.884 , respectively, and $\mathrm{F}_{\mathrm{v}} / \mathrm{F}_{\mathrm{m}}$ and $\Phi_{\mathrm{PSII}}$ were positively correlated with SF $(P<0.05)$ with correlation coefficients of 0.895 and 0.901 , respectively. Moreover, $\mathrm{qP}$ was positively correlated with $\operatorname{EPN}(P<0.05)$ with a correlation coefficient of 0.953 . At the maturity stage, $\mathrm{F}_{\mathrm{v}} / \mathrm{F}_{\mathrm{m}}$ was negatively correlated with grain yield $(P<0.05)$ with a correlation coefficient of -0.935 (Table 3 ).

\section{Discussion}

Chlorophyll is the main participant and carrier of energy conversion in photosynthesis ${ }^{23}$. As important photosynthetic pigments, chlorophyll and carotenoids, which participate in the absorption, transmission, and distribution of photosynthetic light energy, play a key role in plant growth and development ${ }^{24}$. This study showed that chlorophyll $\mathrm{a}$ and $\mathrm{b}$ in rice leaves at the booting, heading, and maturity stages increase with increasing nitrogen application rate, thus indicating that nitrogen deficiency could lead to a decrease in chlorophyll content. This finding is consistent with the research of Gu et al. ${ }^{10}$. Zhang et al. ${ }^{8}$ reported that increased nitrogen application causes an evident increase in carotenoid content in wheat, similar to the results of the present study. This study also indicated that carotenoid increases with the increasing nitrogen application rate at the booting, heading (except for the N0 treatment), and maturity stages. Such findings indicate that nitrogen could significantly 
improve the content of photosynthetic pigments in leaves ${ }^{25}$ and, thus, has positive significance for the absorption of light energy by leaves and increase in photosynthetic rate ${ }^{26}$.

Nitrogen is an important component of chlorophyll and protein in plants. A lack of nitrogen can reduce the absorption of light energy by plants and the activity of the PSII reaction center ${ }^{27}$. Liu et al. ${ }^{28}$ reported that proper nitrogen application rates could improve the PSII activity, photochemical efficiency, and proportion of the open part of the PSII reaction center of rice leaves. These features help plants use captured light energy effectively during photosynthesis and promote the quantum efficiency and photosynthetic rate of PSII. Liu Qifeng's research is similar to the conclusion of this study; different from the results of this study was that the $\mathrm{F}_{\mathrm{v}} / \mathrm{F}_{\mathrm{m}}$ and $\Phi_{\mathrm{PSII}}$ first increased and then decreased with increasing nitrogen application rate within the range of $150-300 \mathrm{~kg} \mathrm{ha}^{-1}$ at the booting stage. When the nitrogen application rate was $225 \mathrm{~kg} \mathrm{ha}^{-1}$, reaching the highest value, which also shows that the proper nitrogen application rate can enhance the photochemical efficiency of rice leaves. The potential active center of PSII could be damaged by excessively low or high nitrogen levels, thereby inhibiting the original reaction process of photosynthesis, negatively affecting the transfer of photosynthetic electrons from the PSII reaction center to the sink source, and resulting in reductions in $\mathrm{F}_{\mathrm{v}} / \mathrm{F}_{\mathrm{m}}$ and $\Phi_{\mathrm{PSII}}{ }^{29}$.

In the present work, as nitrogen application rate increased, ETR at the heading and maturity stages first increased and then decreased, which indicates that the appropriate nitrogen application rate could improve the opening degree of the PSII reaction center of rice functional leaves and increase their light energy utilization rate. This mechanism may be related to the catalytic effect of nitrogen fertilizer on the activity of light-activated enzymes in leaves, which enhances the energy capture efficiency of the PSII reaction center ${ }^{30}$, and is consistent with the results of Zhang et al. ${ }^{31}$.

The present study found that $\mathrm{qP}$ increases gradually as the nitrogen rate increases within the range of $150-300 \mathrm{~kg} \mathrm{ha}^{-1}$ at the heading and maturity stages. This result indicates that an appropriate increase in nitrogen application could increase the proportion of the open part of the PSII reaction center, which is beneficial to charge separation in the PSII reaction center. Charge separation enhances the flow of electrons from the PSII oxidation side to the PSII reaction center, thereby improving the PSII electron transfer capability and ultimately contributing to the increase in PSII quantum yield, which is consistent with the research of Ma Jifeng et al. ${ }^{16}$. Zhang et al. reported ${ }^{31}$ that $\mathrm{qN}$ under high-nitrogen treatment is greater than that under low nitrogen treatment, and surmised that the average opening degree of the PSII reaction center of rice leaves in under high nitrogen treatment was higher than that under low nitrogen treatment. The high electron transfer efficiency and heat dissipation ability of leaves under high nitrogen levels could avoid damage to the photosynthetic mechanism caused by excess light energy and improve their photosynthetic efficiency. This finding, however, is different from the results of the present study. The present results showed that $\mathrm{qN}$ first increases and then decreases with increasing nitrogen application rate within the range of $0-300 \mathrm{~kg} \mathrm{ha}^{-1}$ at the booting, heading, and maturity stages. The reasons behind the differences observed must be further analyzed.

The light quantum absorbed by the PSII reaction center is mainly converted into energy $\Phi_{\mathrm{PSII}}$, PSII regulated energy dissipation $\mathrm{Y}(\mathrm{NPQ})$ and non-regulated energy dissipation $\mathrm{Y}(\mathrm{NO})$ by photochemistry ${ }^{32}$, among which $\mathrm{Y}(\mathrm{NPQ})$ and $\mathrm{Y}(\mathrm{NO})$ represent the most important indices of light protection and light damage, respectively. Long et al. ${ }^{29}$ noted that the NPQ of low nitrogen treatment is higher than that of high nitrogen treatment 20 days after full heading, which indicates that high-nitrogen treated plants have poor self-protection ability in the later stages of rice growth, consistent with the results of the present study. This study found that $\mathrm{Y}(\mathrm{NPQ})$ first increases and then decreases at the three growth stages of rice with increasing nitrogen application. By contrast, $\mathrm{Y}(\mathrm{NO})$ showed the opposite trend. These results demonstrate that the appropriate amount of nitrogen application is conducive to enhance the self-protection ability of plants.

This study noted that SPP and grain yield first increase and then decrease with increasing nitrogen application, thus indicating that an appropriate amount of nitrogen application can promote rice grain yield. As the amount of nitrogen application exceeds a certain level, increases in crop yield, consistent with the results of Gao et al. ${ }^{33}$; nmay be observed. EPN, TGW, and SF first decreased and then increased in the present study, which is ininconsistent with the results of Jiang et al. ${ }^{34}$. The difference found may be related to the variations in basic soil fertility.

Yan et al. ${ }^{18}$ showed that a significant or extremely significant positive correlation may be observed between chlorophyll $\mathrm{a}$ and $\mathrm{b}$ contents and $\mathrm{F}_{\mathrm{v}} / \mathrm{F}_{\mathrm{m}}$ and ETR during rice flag leaf senescence, which contrasts the findings of the present study. The present work found that, at the heading stage, chlorophyll a and $b$ are negatively correlated with $\mathrm{F}_{\mathrm{v}} / \mathrm{F}_{\mathrm{m}}$ and ETR, among which, the former $\mathrm{F}_{\mathrm{v}} / \mathrm{F}_{\mathrm{m}}$ was significant while the latter chlorop ETR was not. These observed differences may be related to the research conditions and subjects. The relationship between most of the fluorescence parameters and contents of chlorophyll a and $b$ in the present study did not show statistical significance, similar to the work of Xu et al. ${ }^{35}$.

Liu et al. ${ }^{17}$ reported that chlorophyll content is positively correlated with SPP at the 5\% significance level and negatively correlated with SF and TGW at the $1 \%$ or $5 \%$ significance levels at the heading stage. Moreover, chlorophyll content was negatively correlated with SF at the $1 \%$ significance level and positively correlated with TGW at the 5\% significance level at the maturity stage, which is different from the results of the present study. The results of the present study showed that chlorophyll content is negatively correlated with SPP, SF, and TGW at the heading stage, but the differences found were not significant. Chlorophyll content was negatively correlated with SF at the maturity stage, but only the relationship between chlorophyll a content and SF showed statistical significance. Chlorophyll content was negatively correlated with TGW, but the differences found were not significant. Moreover, a positive correlation between chlorophyll content and grain yield was observed at the heading and maturity stages, but the differences found were not significant. This finding contrasts the results of Zou et al. ${ }^{36}$, who noted a significant or extremely significant positive correlation between chlorophyll content and grain yield after full heading. Differences among these results may be due to the different materials and conditions used in the experiments. 
The present study found that $\mathrm{F}_{\mathrm{v}} / \mathrm{F}_{\mathrm{m}}$ and $\mathrm{Y}(\mathrm{NO})$ are significantly negatively related to EPN and SPP, respectively, and that $\mathrm{F}_{\mathrm{v}} / \mathrm{F}_{\mathrm{m}}$ and $\Phi_{\mathrm{PSII}}$ are significantly positively related to $\mathrm{SF}$, and $\mathrm{qP}$ was positively correlated with EPN at the $1 \%$ significance level at the heading stage, but no significant correlation was observed between the fluorescence parameters and yield components at the maturity stage, which differs from the results of Guo et al. ${ }^{19}$. Guo et al. showed that no significant relationship could be observed between fluorescence parameters and yield components at the heading stage; however, at the maturity stage, $\mathrm{F}_{\mathrm{v}} / \mathrm{F}_{\mathrm{m}}, \Phi_{\mathrm{PSII}}, \mathrm{qP}$, and $\mathrm{qN}$ in rice leaves were significantly or extremely significantly positively correlated with SF and TGW. This difference may be due to the different materials and conditions used in the experiments. Xu et al. ${ }^{13}$ found that $\mathrm{F}_{\mathrm{v}} / \mathrm{F}_{\mathrm{m}}$ is significantly positively correlated with grain yield at the heading stage. Jiang et al. ${ }^{12}$ reported that $\Phi_{\mathrm{PSII}}$ and qP are significantly positively correlated with grain yield at the heading stage, which is inconsistent with this study. The present study found that grain yield is negatively correlated with $\mathrm{F}_{\mathrm{v}} / \mathrm{F}_{\mathrm{m}}$ and $\Phi_{\mathrm{PSII}}$ and positively correlated with $\mathrm{qP}$ at the heading stage, although the differences observed did not reach significant levels. In addition, only $\mathrm{F}_{\mathrm{v}} / \mathrm{F}_{\mathrm{m}}$ was significantly negatively correlated with grain yield at the maturity stage. These differences and their causes need further verification and analysis.

\section{Conclusions}

Moderate fertilizer application can ensure high photosynthetic pigment content, enhance the ability of light energy capture, improve the photochemical efficiency and proportion of the open part of the reaction center of PSII, and promote the quantum efficiency and self-protection ability of PSII. These effects help avoid damage caused by excess light energy to the photosynthetic mechanism and promote high efficiency and yield. Significant correlations were observed among photosynthetic pigments, fluorescence characteristics, and yield and its components. The most suitable application amount of nitrogen fertilizer was $150 \mathrm{~kg} \mathrm{ha}^{-1}$, and the yield of rice was $11,882 \mathrm{~kg} \mathrm{ha}^{-1}$. The regression equation we obtained revealed that the best nitrogen rate was $168.16 \mathrm{~kg} \mathrm{ha}^{-1}$ and the highest yield was $11,804.87 \mathrm{~kg} \mathrm{ha}^{-1}$.

\section{Material and methods}

The collection of rice plant materials. In this study, field studies on rice cultivation, including the collection of rice plant materials, are in line with relevant institutional, national and international guidelines and legislation.

Experimental site. The experiment was conducted in Zhaibi Village, Jiuzhou Town, Huangping County, Guizhou Province, China ( $\left.26^{\circ} 59^{\prime} 44.59^{\prime \prime} \mathrm{N}, 107^{\circ} 43^{\prime} 58.90^{\prime \prime} \mathrm{E}\right)$, in 2019 . The planting area had a subtropical humid climate, an altitude of $698 \mathrm{~m}$, and an annual average temperature of $15.7^{\circ} \mathrm{C}$. The frost-free period and average annual rainfall were 268 days and $1200 \mathrm{~mm}$, respectively.

Soil properties and plant materials. The soil properties of the experimental field were as follows: $\mathrm{pH}$ of 5.02 , organic matter of $18.38 \mathrm{~g} \mathrm{~kg}^{-1}$, alkali hydrolyzed nitrogen of $209.50 \mathrm{mg} \mathrm{kg}^{-1}$, available phosphorus of $4.56 \mathrm{mg} \mathrm{kg}^{-1}$, available potassium of $65.73 \mathrm{mg} \mathrm{kg}{ }^{-1}$, total nitrogen of $2.62 \mathrm{~g} \mathrm{~kg}^{-1}$, total phosphorus of $0.29 \mathrm{~g} \mathrm{~kg}^{-1}$, and total potassium of $12.31 \mathrm{~g} \mathrm{~kg}^{-1}$. Two rice cultivars, Qyou6 and Yixiangyou2115, were employed in this study. Qyou6 was bred by the Chongqing Seed Company, and Yixiangyou2115 was selected by the Yibin Academy of Agricultural Sciences and Sichuan Agricultural University. The leaf color of the former was darker than that of the latter.

Experimental details. A split-plot design with three replicates was adopted in this experiment. Two cultivars (Qyou 6 [V1] and Yixiangyou 2115 [V2]) were assigned to the main plots, and four nitrogen rates (0 [N0], 75 [N1], 150 [N2], 225 [N3], and $300 \mathrm{~kg} \mathrm{ha}^{-1}$ [N4]) were assigned to the subplots. The size of each subplot was $25.9 \mathrm{~m}^{2}$. Nitrogen fertilizer was split applied as follows: $35 \%$ basal, $20 \%$ at 7 days after transplanting, $30 \%$ at the panicle initiation stage, and $15 \%$ at the booting stage. Moreover, $96 \mathrm{~kg} \mathrm{P}_{2} \mathrm{O}_{5} \mathrm{ha}^{-1}$ and $67.5 \mathrm{~kg} \mathrm{~K}_{2} \mathrm{O} \mathrm{ha}^{-1}$ were applied as basal fertilizers before transplanting for all treatments, and $67.5 \mathrm{~kg} \mathrm{~K}_{2} \mathrm{O} \mathrm{ha}^{-1}$ was applied at the panicle initiation stage. Urea, superphosphate, and potassium chloride were used as nitrogen, phosphorus, and potassium fertilizers, respectively. A ridge covering measuring $30 \mathrm{~cm}$ in height and $20 \mathrm{~cm}$ in width was constructed around the subplots. This covering was pressed up to $30 \mathrm{~cm}$ underground to prevent the infiltration of water and fertilizer. A $50 \mathrm{~cm}$-long walkway was established between replicates for field operation and investigation. The rice seedlings were raised on 18 April and transplanted on May 27 with a row spacing of $30 \mathrm{~cm} \times 20 \mathrm{~cm}$. One seedling was planted per hole. In the field, shallow water was maintained at the greening stage, and wet irrigation was carried out at the tillering stage. The water was cut off naturally to dry the field when the seedling number reached $85 \%$ of the expected panicle number. After jointing, water was irrigated into the field, and shallow water was maintained until the heading stage. Intermittent irrigation was carried out during the filling and ripening periods, and the water was cut off and dried 10 days before harvest. Diseases and pests in rice were controlled in a timely manner.

Plant sampling and parameter determination. Determination of photosynthetic pigment content. Samples were collected at the jointing (24 July), heading (12 August), and maturity (14 September) stages. Leaves aged 1.5 were collected at the jointing stage, and flag leaves were collected at the heading and maturity stages. The samples were collected from 9:00 to 10:00 a.m. for each treatment. Here, four leaves were collected, placed in self-sealing bags, marked, and then quickly placed in a refrigerator. The $80 \%$ acetone extraction method was used to determine the contents of various pigments. The absorbance of the extraction solution was 
measured at 663,645 , and $470 \mathrm{~nm}$, and the contents of chlorophylls a and b and carotenoids in leaves per unit mass were calculated according to the Arnon correction method ${ }^{37}$.

Determination of leaf fluorescence parameters. Leaf fluorescence parameters were measured by a PAM-2500 portable modulated chlorophyll fluorescence meter at the booting (23 July), heading (11 August), and maturity (13 September) stages. Leaves were selected using the protocol adopted for photosynthetic pigment content determination. The initial fluorescence $\left(\mathrm{F}_{\mathrm{o}}\right)$ and maximum fluorescence $\left(\mathrm{F}_{\mathrm{m}}\right)$ under dark adaptation were measured, then, the maximal quantum yield of PSII $\left(\mathrm{F}_{\mathrm{v}} / \mathrm{F}_{\mathrm{m}}\right)$ was calculated using the formula $\left(\mathrm{F}_{\mathrm{m}}-\mathrm{F}_{\mathrm{o}}\right) / \mathrm{F}_{\mathrm{m}}$. Measurement of the minimum fluorescence $\left(\mathrm{F}_{\mathrm{o}}{ }^{\prime}\right)$, maximum fluorescence $\left(\mathrm{F}_{\mathrm{m}}{ }^{\prime}\right)$, and real-time fluorescence yield $(\mathrm{F})$ under light adaptation revealed the actual quantum yield of PSII $\left(\Phi_{\text {PSII }}\right)$, photochemical quenching coefficient $(\mathrm{qP})$, non-photochemical quenching coefficient $(\mathrm{qN})$, quantum yield of non-regulatory energy dissipation at PSII(Y(NO)), quantum yield of regulatory energy dissipation at PSII (Y(NPQ)), and relative electron transfer rate at PSII (ETR).

Measurement of yield and its components. At the maturity stage, rice yield and its related components were determined by analyzing 90 hills in each subplot and adjusted to a moisture content of $0.135 \mathrm{~g} \mathrm{H}_{2} \mathrm{O} \mathrm{g}^{-1}$ fresh weight. Six representative hills were selected on the basis of the average number of stems and tillers in the field survey as test samples to investigate the yield components of rice.

Statistical analysis. The data were analyzed by SAS9.0 (SAS Institute, Cary, NC, USA).

\section{Data availability}

All data generated or analysed during this study are included in the article.

Received: 26 May 2020; Accepted: 22 March 2021

Published online: 05 April 2021

\section{References}

1. Li, Y. Studies on the mechanisms of the effect of different nitrogen supplies on photosynthesis and photosynthetic nitrogen use efficiency of rice plants. Ph.D. dissertation, Nanjing Agricultural University, Nanjing, Jiangsu, China ( 2011).

2. Cao, G.L., Zhang, Y.Y., Piao, Z.Z. \& Han, L.Z. Evaluation of tolerance to low $\mathrm{N}$-fertilized level for rice type. Journal of plant genetic resources.7, 316-320(2006).

3. Zhang, W.Y. Mechanism underlying water and nitrogen regulating spikelet development and grain filling of rice. Ph.D. dissertation, Yangzhou University, Yangzhou, Jiangsu, China(2018).

4. Lin, Z. C. et al. Effects of located nitrogen application and nitrogen application after on rice yield and nitrogen use efficiency in the Taihu Lake area China. Chin. J. Rice Sci. 24, 271-277 (2010).

5. Tang, Y. L., Wang, J. H., Huang, J. F., Wang, R. C. \& He, Q. X. Variation law of hyperspectral data and chlorophyll and carotenoid for rice in mature process. Trans. Chin. Soc. Agric. Eng. 19, 167-173 (2003).

6. Wang, X.J. Plant physiology; Higher Education Press: Beijing, China.; pp: 71-75 (2019).

7. Cheng, Z. H. \& Liu, L. Y. Detection of vegetation light use efficiency based on chlorophyll fluorescence spectrum. Trans. Chin. Soc. Agric. Eng. 26, 74-80 (2010).

8. Zhang, X. C. \& Shangguan, Z. P. Effect of nitrogen fertilization on photosynthetic pigment and fluorescence characteristics in leaves of winter wheat cultivars on dryland. J. Nuclear Agric. Sci. 21, 299-304 (2007).

9. Zhang, Y. F. et al. Response characteristics of plant growth and leaf photochemical activity of sugr beet seedlings to different nitrogen application levels. J. Nuclear Agric. Sci. 27, 1391-1400 (2013).

10. Gu, J. F. et al. Effect of the mutant with low chlorophyll content on Photosynthesis and yield in rice. Acta Agron. Sin. 42, 551-560 (2016).

11. Liu, R. X., Wang, Y. H., Chen, B. L., Guo, W. Q. \& Zhou, Z. G. Effect of nitrogen levels on Photosynthesis and chlorophyll fluorescence characteristics under drought stress in cotton flowering and boll-forming. Acta Agron. Sin. 34, 675-683 (2008).

12. Jiang, L. L., Zhang, Z. X. \& Zheng, E. N. Effects of different fertilizations on chlorophyll fluorescence characteristics and the yield of rice in black soils in cold region. J. Irrigat. Drainage. 37, 75-80 (2018).

13. Xu, G. W., Lu, D. K., Wang, H. Z., Chen, M. C. \& Li, Y. J. Coupling effect of wetting and drying alternative irrigation and nitrogen application rate on photosynthetic Characteristics of rice leaves. J. Plant Nutr. Fertiliz. 23, 1225-1237 (2017).

14. Su, W. et al. Effects of straw returning and nitrogen application rate on dry matter accumulation and yield of indica hybrid rice in karst region. J. Nuclear Agric. Sci. 33, 1856-1864 (2019).

15. Ou, D. et al. Effects of nitrogen application rate and mechanical-transplanting density on Photosynthetic Characteristics and yield of hybrid indica rice with bowl mechanical-transplanting method. J. Southern Agric. 50, 1442-1450 (2019).

16. Ma, J. F. et al. Relationship between nitrogen content and fluorescence parameters in rice. Chin. J. Rice Sci. 21, 65-70 (2007).

17. Liu, J. et al. Mapping of QTLs for chlorophyll content and panicle traits and their relationship in rice (Oryza sativa L.). J. Shenyang Agric. Univ. 49, 641-648 (2018).

18. Yan, S. M. et al. Study on chlorophyll fluorescence characteristics of hybrid rice leaves during senescence. Jiangsu Agric. Sci. 42, 49-51 (2014).

19. Guo, X. P., Wang, F., Wang, Z. C., Huang, S. S. \& Liu, W. Effects of irrigation modes on yield and chlorophyll fluorescence characteristics after heading stage of rice. J. Irrigat. Drainage. 3, 1-6 (2017).

20. Zhang, S. R. A discussion on chlorophyll fluorescence kinetic parameters and their significance. Chin. Bulletin Botany. 16, 444-448 (1999).

21. Krause, G. H. \& Weis, E. ChlorophyII fluorescence and photo-synthesis:The basics. Plant Physiol. 42, 313-349 (1991).

22. Genty, B. E., Briantais, M. J. \& Baker, N. R. The relationship between the quantum yield of photosynthetic electron transport and quenching of chlorophyll fluorescence. Biochem Biophys Acta. 990, 87-92 (1989).

23. Lin, Z. H. et al. $\mathrm{CO}_{2}$ assimilation, ribulose-1, 5-bisphosphate carboxylase/oxygenase, carbohydrates and photosynthetic electron transport probed by the JIP-test, of tea leaves in response to phosphorus supply. BMC Plant Biol. 9, 43 (2009).

24. Yang, X. H. et al. Tolerance of photosynthesis to photoinhibition, high temperature anddrought stress in flag leaves of wheat: a comparison between ahybridization line and its parents grown under field condition. Plant Sci. 171, 389-397 (2006).

25. Kathju, S., Burman, U. \& Garg, B. K. Influence of nitrogen fertilization on water relations, photosynthesis, carbohydrate and nitrogen metabolism of diverse pearl millet genotypes under arid conditions. J. Agric. Sci. 137, 307-318 (2001). 
26. Barbara, L., Andrea, S., Enrico, B. \& Flavia, N. I. Antioxidative defense system, pigment composition, and photosynthetic efficiency in two wheat cultivars subjected to drought. Plant Physiol. 119, 1091-1100 (1999).

27. Jin, W. W., Wang, Y., Zhang, H. H. \& Sun, G. Y. Effects of different nitrogen rate on the function of flue-cured tobacco seedlings photosystemII under drought stress. J. Nanjing Agric. Univ. 35, 21-26 (2012).

28. Liu, Q. F. \& Xu, S. Q. Response of fluorescence parameters and photosynthetic traits of rice to different nitrogen application under sufficient irrigation. J. Irrigat. Drainage. 37, 6-12 (2018).

29. Long, J. R., Ma, G. H., Wan, Y. Z., Song, C. F. \& Sun, J. Effects of nitrogen application on chlorophyll fluorescence characteristic in flag leaf of super hybrid rice at late growth stage. Chin. J. Rice Sci. 25, 501-507 (2011).

30. Guo, F. effects of different light intensity on Photosynthetic Characteristics in leaves of high yield winter wheat. Ph.D. dissertation, Shandong Agricultural University, Taian, Shandong, China. (2008).

31. Zhang, Z. X., Zheng, E. N., Wang, C. M. \& Fu, N. H. Effect of different water and nitrogen levels on chlorophyll fluorescence parameters and photosynthetic characteristics of rice. Trans. Chin. Soc. Agric. Machin. 48, 176-183 (2017).

32. Genty, B., Briantais, J. M. \& Baker, N. R. The relationship between the quantum yield of photosynthetic electron transport and quenching of chlorophyll fluorescence Biochimica et Biophysica Acta (BBA). General Subjects 990, 87-92 (1989).

33. Gao, W. et al. Effects of nitrogen rate on grain yield and nitrogen use efficiency of different phases of super hybrid rice varieties. Hybrid Rice. 31, 59-64 (2016).

34. Jiang, P., Liu, M., Qin, J., Xiong, H. \& Xu, F. X. Effects of nitrogen application rate on yield and grain quality of Super Hybrid Rice. China Rice 23, 102-106 (2017).

35. Xu, L. et al. Flag leaf photosynthetic characteristics, changes in chlorophyll fluorescence parameters, and their relationship with yield of winter wheat sowed in spring. Chin. J. Appl. Ecol. 27, 133-142 (2016).

36. Zou, D.T.et al. ,. Researc on relationship between anti-aging inde and panicle agronomic taits, yield in cold super-rice. Research of Agricultural Modernization. 31, 742-745 (2010).

37. Zhang, Z.L., Qu, W.J. \& Li, X.F. Experimental guidance of plant physiology; Higher Education Press: Beijing, China. pp: 144-159(2009).

\section{Acknowledgements}

This work was supported by the Subproject of Special fund project for Scientific Research of Public Welfare Industry (Agriculture) (201503118-03), the National Natural Science Foundation of China (31360311, 31160263), the Scientific and Technological Innovative Talents Team for Cultivation and Eco-Physiology Research of Featured Grain and Oil Crops in Guizhou Province (Grant no. Qiankehe Platform Talents [2019]5613), the Talents Program of High Level and Innovative in Guizhou Province (Grant no. Qiankehe Platform Talents [2018]5632), the Agricultural Scientific and Technological Project in Guizhou Province (QiankeheZC[2019]2303, QiankeheZC[2016]2563, Qiankehe NY[2013]3005, Qiankehe NY[2011]3085), the regular higher education institution project of key laboratory of genetic improvement and physiology and ecology of grain and oil crops of Guizhou Province of China(Grant no. KY[2015]333), and the Construction Program of Biology First-class Discipline in Guizhou Province (GNYL [2017]009).

\section{Author contributions}

Y.F. and G.X. conceived the experiments. X.W., J.L., S.P., Q.L., Z.H. and W.L. performed the experiments. J.P. analysed the data and wrote the manuscript. All authors have read and approved the final manuscript.

\section{Competing interests}

The authors declare no competing interests.

\section{Additional information}

Correspondence and requests for materials should be addressed to Y.F. or G.X.

Reprints and permissions information is available at www.nature.com/reprints.

Publisher's note Springer Nature remains neutral with regard to jurisdictional claims in published maps and institutional affiliations.

(c) (i) Open Access This article is licensed under a Creative Commons Attribution 4.0 International (c) License, which permits use, sharing, adaptation, distribution and reproduction in any medium or format, as long as you give appropriate credit to the original author(s) and the source, provide a link to the Creative Commons licence, and indicate if changes were made. The images or other third party material in this article are included in the article's Creative Commons licence, unless indicated otherwise in a credit line to the material. If material is not included in the article's Creative Commons licence and your intended use is not permitted by statutory regulation or exceeds the permitted use, you will need to obtain permission directly from the copyright holder. To view a copy of this licence, visit http://creativecommons.org/licenses/by/4.0/.

(c) The Author(s) 2021 